\title{
Restitution and human sleep: A critical review
}

\author{
J. A. HORNE \\ Department of Human Sciences, Loughborough University \\ Loughborough, Leicestershire LE11 3TU, England
}

\begin{abstract}
It is often assumed that human non-REM sleep, especially its apparently more intense form of slow-wave sleep (SWS), is associated with large increases in body restitutional processes, for example, protein synthesis. However, findings from total sleep deprivation appear only to support a brain restitutional role for human sleep and not one of body restitution. Although rises in human growth hormone (hGH) release during SWS might support a body restitutional role, the variety of complex actions of hGH indicate that other effects, particularly the redistribution of energy substrates, are likely. Sleep hGH release may be a misleading factor in the understanding of SWS function. Increases in protein synthesis during human sleep are unlikely for several reasons. The elevation of mitosis which can occur in sleep is probably a concomitant phenomenon. While relaxed wakefulness should provide for man's body restitutional need, the lack of such a relaxed state in certain mammals may necessitate that sleep fulfills this need for these animals. Although REM sleep, alone, is generally considered to be for cerebral restitution, evidence in support of this viewpoint needs qualification. It is argued that non-REM sleep, especially SWS, is of equal benefit to the human brain.
\end{abstract}

Among sleep researchers, the opinion is generally held that sleep is a state of enforced rest and energy conservation, wherein both body and brain can recover from the wear and tear of wakefulness. Ostensibly, non-REM (nondreaming) sleep is considered to be oriented towards promotion of the synthetic processes of growth and repair in the body, and REM (dreaming) sleep is believed to be directed towards increases in synthetic processes within the brain, including the consolidation of memory. The purpose of this review is to appraise these assumptions for the functions of sleep, with particular regard to man. Although no firm conclusions can yet be drawn about these functions, it would appear that the results from a variety of experimental studies which are often used in support of these assumptions may be used for alternative interpretations.

As already discussed in more detail elsewhere (Horne, 1977), most theories of sleep function cover the majority of mammalian species, but such a universality of function cannot necessarily be assumed. If sleep does provide for recovery following wakefulness, the differing life-styles and evolutionary adaptations of the mammals may result in subtle differences in sleep function. For this reason, the ensuing discussion will tend to confine itself to man.

Some insight into possible functions of human sleep may be gained by examining the effects of total sleep deprivation. From reviews of this area by Horne (1978), Naitoh (1975), and Wilkinson (1965), it appears that the main findings are not so much among the physiological measures of somatic functioning but are within the performance, behavioral, and EEG changes. Although the range of physiological indices used during sleep deprivation has not been exhaustive, it would so far seem that in man, at least, sleep may be more oriented towards the brain than the body.

If human sleep aids restitution from the various impositions of wakefulness, then there may be an interaction between wakefulness and subsequent sleep. Reports on the effects of the course of time upon REM sleep and what now might be considered a more intense form of non-REM sleep, namely deep or slow-wave sleep (SWS) stages 3 and 4, indicate that a total night's SWS is positively correlated with the duration of preceding wakefulness (Karacan, Williams, Finley, \& Hursch, 1970; Webb \& Agnew, $1971,1977)$. On the other hand, there is no such correlation between wakefulness and subsequent REM sleep (Agnew \& Webb, 1973; Webb \& Agnew, 1977). Thus, while both SWS and REM sleep are subject to circadian influences, these findings suggest that SWS may be more oriented towards recovery from wakefulness than is REM sleep. This suggestion, together with the predominately CNS effects of sleep deprivation, indicate that SWS may well have benefits for the brain.

\section{SWS and Human Growth Hormone}

Human growth hormone (hGH) is evident in relatively large amounts in the plasma during the early sleep period, usually during SWS (Honda, Takahashi, Takahashi, Azumi, Irie, Sakuma, Tsushima, \& Schizume, 1969; Takahashi, Kipnis, \& Daughaday, 1968). Although the effects of hGH are delayed, and among the mammals such a sleep-related release may be unique to certain primates (Quabbe, 1977; Sassin, 
1977), the presence of this hormone during human SWS has tended to encourage the opinion that SWS is mainly for body tissue growth and restitution (Hartmann, 1973; Oswald, 1969, 1976). Furthermore, the brain is often overlooked or excluded as a beneficiary of SWS, or for being a site of action for hGH.

Undoubtedly, in human sleep, there is a link between hGH peaks and SWS. For example, Karacan, Rosenbloom, Londono, Williams, and Salis (1974) found that afternoon naps contain both SWS and a hGH peak, whereas morning naps mostly contain REM sleep and stage 2 sleep with no hGH peak. Also, Vigneri, Pezzino, Squatrito, Calandara, and Marricchiolo (1974) reported that in schizophrenics there is both a disturbance in sleep hGH output and in SWS. A similar finding was reported by Schilkrut, Chandra, Osswald, Ruther, Baartüssar, and Matussek (1975) in patients with depression. But, from reports of several other studies, such a SWS-hGH link has to be qualified. For example, SWS deprivation results in smaller, but still significant, amounts of hGH release during the remaining sleep (Karacan, Rosenbloom, Williams, Finley, \& Hursch, 1971; Sassin, Parker, Johnson, Rossman, Mace, \& Gotlin, 1969); hGH-inhibiting factor (somatostatin) or an elevation in plasma-free fatty acids will suppress the sleep hGH release but not SWS (Lipman, Taylor, Schenk, \& Mintz, 1972; Lucke, Höffken, \& von zur Mühlen, 1976); sleep hGH can be elevated without there being any significant quantitative effect upon SWS (Adamson, Hunter, Ogunremi, Oswald, \& Percy-Robb, 1974); finally, hGH-deficient children have normal SWS levels but no sleep-hGH release (Orr, Vogel, Stahl, Griffiths, \& Seely, 1977).

The peak levels of sleep-hGH output are relatively large and comparable with those found following 20 min of exercise at $50 \%$ of $\mathrm{VO}_{2}$ maximum, or following a standard arginine infusion test (Sutton \& Lazarus, 1976). Although lying down during relaxed wakefulness will cause a small (approximately 17\%) elevation of plasma hGH levels, during sleep these levels will increase by about a further $250 \%$ (Alford, Baker, \& Burger, 1973). However, in sleep, unlike in wakefulness, the sleep-hGH release bears no relation to normal plasma levels of free fatty acids, glucose, or amino acids which are present at the time. Seemingly, the sleep-hGH release is under neural rather than metabolic control, as during sleep hGH does not show its characteristic suppression in response to glucose infusion (Parker \& Rossman, 1971; Schnure, Raskin, \& Lipman, 1971).

Although the significance of this sleep-hGH release is not really clear, it is often assumed that, in the adult, the main function of hGH is for the promotion of protein synthesis, and hence that the prime function of SWS is to provide for high levels of such synthesis and related anabolic processes. hGH is a difficult hormone to study as there are no target organs, but many target tissues. Also, it is not hGH itself which is effective, but a group of mediators, the somatomedins, which have variable effects. There are marked interspecies differences in the structure, function, and probable receptors of growth hormone. Furthermore, many of its actions are delayed and biphasic (Blackard \& Andrews, 1974). For the first 2-3 $\mathrm{h}$ after release, it is insulin-like, promoting hypoglycaemia; then it develops anti-insulin-like activity, promoting hyperglycaemia.

The different modes of action of hGH on various target tissues are fairly well known (Hunter, 1972; Kostyo \& Nutting, 1974; Martin, 1977). However, the primary role of $\mathrm{hGH}$ is far from clear and the instigation of protein synthesis is only one of the hormone's many functions. Under normal circumstances, in the adult, hGH promotes: uptake of amino acids and their incorporation into protein; lipid mobilization and catabolism; and glucose formation from hepatic glycogen and pyruvate. The hormone also modifies the gluconeogenic influence of the glucocorticoids. It is really a "permissive" rather than an initiating hormone (Martin, 1977), as it prolongs and intensifies metabolic actions. Hunter (1972) has proposed that a major role for hGH is a protein-sparing action mediated by both fat mobilization and the regulation of body energy stores. Recently, Quabbe (1977) has reported that sleep-hGH output is diminished or absent in the obese, suggesting that sleep-hGH release may be associated with the long-term regulation of lipid stores.

Unfortunately, there have been few investigations into the roles growth hormone might have for the brain, assuming that it can pass the blood-brain barrier. From studies of artificial elevations in growth hormone during sleep in the cat, Drucker-Colin, Spanis, and Rojas-Ramerez (1977) and Stern and Morgane (1977) have reported that following 3-7 h after hormone infusion there are elevations in, or changes in the distribution of, REM sleep. Both groups of authors suggest that these changes may represent an increase in brain protein synthesis dui... REM sleep. However, measurements of this synthesis were not performed. Furthermore, interactions between growth hormone and REM sleep are confounded by Stern and Morgane's (1977) findings that hypophysectomized cats do not show any significant decreases in REM sleep. The authors conclude (p. 383) that growth hormone may be a sufficient, but not necessary, factor for the occurrence of REM sleep, and there is as yet no clear evidence of REM sleep being associated with high levels of brain protein synthesis. This latter point is supported by Weitzman $(1977$, p. 403) in his neurochemical review of sleep and memory.

In concluding this discussion on sleep-hGH release, it would appear that, with the functional complexity of hGH and a possible change in control mechanisms 
from waking to sleeping, any hypothesis which proposes that sleep-hGH is directed towards body tissue restoration and protein synthesis needs further support. Perhaps the release is a misleading epiphenomenon in our understanding of SWS or non-REM sleep function. For example, target sites may be less receptive to the effects of hGH during sleep and therefore increased release of this hormone may be necessary. An alternative reason might proceed along the following lines. Prolonged physical rest will bring an increase in muscle tissue breakdown. Even though the normal sleep length of man may be too short a time for such activities to occur to any extent, sleep may be long enough for precursory procedures to begin. Thus, perhaps the sleep-hGH release may be anticipatory in this respect, with its protein-sparing action directed against possible loss of protein.

\section{Tissue Restoration and Protein Synthesis \\ During Sleep}

Increases in tissue growth imply an increase in synthesis of new protein, rather than just a resynthesis of protein from amino acids produced by the breakdown of old tissue protein. If this latter situation alone were apparent, then there would be no net increase in protein; that is, no growth. New synthesis requires an increased input of amino acids into the cell, and thus any increase in tissue growth during sleep would necessitate elevations both in plasma levels of amino acids and in active uptake of these substances by the cell. However, a normal dietary regime for most people entails fasting for several hours prior to the usual sleep time, leading to reduced plasma amino acid levels during the sleep period (Feigin, Klainer, \& Beisel, 1967). Since a major governing factor of protein synthesis now appears to be the availability of amino acids to the cell (Waterlow, Garlick, \& Millward, 1978), the reduction of plasma amino acid levels during sleep would mitigate against heightened levels of new protein synthesis at this time. Such a conclusion is borne out by Garlick, Clugston, Swick, Meinertzhagen, and Waterlow (1978). Here, subjects were fed for $12 \mathrm{~h}$, only in the daytime, and this led to a $(29 \%)$ drop in protein synthesis rates during the 12-h nighttime period. However, there was an even greater $(40 \%)$ drop in protein degradation at this time, producing an overall picture of protein conservation at nighttime. Unfortunately, sleepwakefulness records were not taken. The authors stated that if protein synthesis was to be maintained at daytime values during nighttime, then continuous food intake would be necessary. This statement is further supported by this group's earlier findings (Golden \& Waterlow, 1977) that continuous infusion of foodstuffs results in no change in protein metabolism over $24 \mathrm{~h}$.
Another factor which must be appreciated, if a body restitutional role for human sleep is to be entertained, concerns the energy cost of any elevation in new protein synthesis rates. Although the actual energy cost of protein synthesis per se, that is, the formation of the peptide bonds between amino acids, probably accounts for only about $10 \%-15 \%$ of resting metabolism (Waterlow et al., 1978), the combined energy cost of all aspects of protein synthesis, including the active transport of amino acids into the cell, is apparently much higher (Young, Steffee, Pencharz, Winterer, \& Scrimshaw, 1975). If protein synthesis and its precursory activities were to occur at a high rate during human sleep, then metabolism would be expected to rise above normal resting levels. But Brebbia and Altshuler (1965), Kreider, Buskirk, and Bass (1958), and Webb and Hiestand (1975) have shown that metabolic rate (oxygen consumption) for man during sleep tends to be about 5\%-10\% lower than for relaxed wakefulness-findings incompatible with high rates of protein synthesis.

Formation of the peptide bonds could proceed at elevated levels during sleep without a significant change in metabolism, but high levels of available amino acids within the cell would be necessary. However, the cell does not store these substances for any length of time without utilizing them, and, as plasma levels of amino acids are low during sleep, the amino acids necessary for protein synthesis would have to come from within the cell as a product of protein degradation. Therefore, in these circumstances, any heightened protein synthesis would be balanced by elevations in protein degradation within the cell, resulting in no net increase in protein or in growth.

Many mammals, when not asleep, are highly active and spend much of their wakefulness in feeding behavior. When satiated, they tend to sleep, and here there may be elevations both in plasma amino acid levels and in protein synthesis, at least in the early part of sleep. Assuming this to be so, for the moment, it could be argued that if the available energy supply to the cell, that is, ATP, were to be considered to be oriented either towards energy for muscle movement, feeding, etc., or towards more anabolic processes such as protein synthesis, then a mammal engaged in active wakefulness may not have sufficient ATP reserves available for high levels of these anabolic processes. During resting, these processes could proceed at a higher rate, and, in the absence of sufficient amounts of relaxed wakefulness, enforced rest by way of sleep might occur.

Such an argument may apply to all or part of the sleep of active mammals, depending upon the length and frequency of sleep episodes. But it is unlikely to apply to man as, despite the fact that amino acid availability limits protein synthesis rates during sleep, man is able to demonstrate prolonged periods of re- 
laxed wakefulness, wherein high levels of anabolism can occur. So there is no reason to suggest that ATP levels are low during the majority of human wakefulness, unless an individual is particularly active throughout wakefulness. Thus, given adequate amino acid availability, protein synthesis can proceed, in man, at high levels during either sleep or relaxed wakefulness. But Adam and Oswald (1977) consider that this is not so for man and other mammals, as these authors propose that sleep provides for particularly high levels of ATP.

This latter proposal of theirs will now be examined in more detail, and the assumption will be made, again for the moment, that there is no constraint to protein synthesis during sleep through reduced amino acid availability. Adam and Oswald base their hypothesis upon Atkinson's $(1968,1970)$ concept of cellular energy charge-that the higher the charge, the more biosynthesis is favored. This charge, they claim, is higher in sleep than in wakefulness, and, because of an apparent acceleration in protein synthesis with increasing energy charge, their estimated $15 \%-20 \%$ increase in energy charge from waking to sleep will produce a much larger increase in protein synthesis. Although these estimates for energy-charge levels have been borne out by Durie, Adam, Oswald, and Flynn (1978) using rat tissue, it is unlikely that similar findings would be apparent in humans, for the following reason. While awake, rats are active and show little physical relaxation (Borbély, 1978; Garma \& Verley, 1969). For rodents, sleep appears to be a state of enforced immobility and bringer of rest. Thus, in the rat, energy-charge levels may be kept low during wakefulness through physical activity, and it is not surprising that these levels rise during sleep. The evidence which Adam and Oswald (1977) and Durie et al. (1978) are unable to produce is whether or not sleep can provide for significantly higher energy-charge and consequent protein synthesis levels than can relaxed wakefulness, especially in man. Indeed, Adam and Oswald's hypothesis may well apply to the rat and other similarly active mammals, but man, for example, may have to be excluded.

A second problem which arises with this energycharge hypothesis, if it is to be applied to human sleep, is that although a high-energy charge may favor an increase in protein synthesis, the metabolic demand of this synthesis will soon reduce the charge level and consequently the rate of protein synthesis, unless the resynthesis rate of ATP from ADP increases. Such an increase will cause a significant elevation of metabolism. But, as already stated, in man oxygen consumption is lower in sleep than in relaxed wakefulness. Even though the slight increase in overall muscle relaxation that occurs from wakefulness to sleep in man (Jacobson, Kales, Lehmann, \& Hoedemaker, 1964) might "release" energy sub- strates for increased protein synthesis without apparent change in overall oxygen consumption, the reduced metabolism of sleep, compounded with the energy requirement of all aspects of protein synthesis, would not support substantial increases in protein synthesis during sleep.

\section{Mitotic Rates During Sleep}

A further apparent source of support for a body restitutional role for human non-REM sleep, particularly SWS, comes from reports on the circadian rhythm of mitosis. Studies on rodents, of liver tissue (Halberg \& Barnum, 1961), of bone marrow, and reticulocytes (Clark \& Korst, 1969), and studies on humans, of epidermis (Cooper, 1939; Fisher, 1968) and of bone marrow (Mauer, 1965), all report circadian increases in mitosis at times often commensurate with the early sleep period. Although these studies did not make any objective measures of sleep, it is clear in the human studies that while some subjects had mitotic peaks in the earlier part of sleep, others had such peaks well before the normal sleep period. Fisher (1968) hypothesized that the main controlling factors of mitosis are plasma levels of corticosteroids and adrenaline, with increases in both hormones reducing mitosis; elevation of these hormones by daytime exercise delayed the mitotic peak until later in the sleep period. Adrenal corticosteroid output normally reaches a circadian peak between 0600 and $0800 \mathrm{~h}$, troughing in the late evening, and this rhythm is sleep independent (Weitzman, 1976). Therefore, increases in mitosis during the early sleep period may only be concomitant with SWS and really be a reflection of the sleep-independent low levels of corticosteroid output.

With regard to the studies of mitotic rates in rodents, it should be remembered that these animals are very active during wakefulness. Thus, if activity increases corticosteroid output and decreases mitosis, then naturally there will be higher mitotic rates during sleep than during wakefulness in the rat. Whether or not the sleep-hGH release has any direct influence upon mitosis during sleep is a matter which still remains to be seen. As the rat does not apparently have any growth hormone elevations during its sleep, but both man and rat have mitotic peaks during sleep, hGH may not have any major role in determining mitotic levels.

\section{Exercise, Physiological Stress, and Subsequent Sleep}

The findings by Baekeland and Lasky (1966), Shapiro, Griesel, Bartel, and Jooste (1975), and Zloty, Burdick, and Adamson (1973) of increased SWS following daytime exercise have also been used in support of a body restitution hypothesis for SWS. But studies by Adamson et al. (1974), Horne and Porter 
(1976), Moses, Lubin, Naitoh, and Johnson (1977), Walker, Floyd, Fein, Cavness, Lualhati, and Feinberg (1978) and Zir, Smith, and Parker (1971) all refute these effects. Two of these investigations assessed plasma levels of sleep-hGH output; Adamson et al. (1974) reported an hGH increase above normal sleep levels, and Zir et al. (1971) found no such change.

Horne and Porter (1976) took into consideration individual differences in fitness and work output, as well as the slow-wave activity to be found in stage 2 sleep. It was found that moderate to heavy exercise did not significantly affect the sleep EEG, unless the exercise was performed in the latter part of the day, whereupon the first $1-2 \mathrm{~h}$ of sleep showed a small increase of SWS, balanced by a reciprocal decrease of SWS later in the night. The authors concluded that, as might be expected, the exercise recovery processes began with the termination of exercise and intruded into sleep, rather than required general or specific types of sleep.

Moses et al. (1977) assessed the effects of exercise combined with $40 \mathrm{~h}$ of sleep loss upon recovery sleep. Every $1 \mathrm{~h}$ in 4, an experimental group exercised on a bicycle ergometer and a control group relaxed on a bed. Comparisons of the recovery sleep showed no significant differences between the groups in the amounts of SWS or in any other sleep parameter.

Probably the most systematic study was by Walker et al. (1978), who recorded the sleep of runners and nonrunners under both running and nonrunning conditions. No significant changes were found in any sleep parameter between running and nonrunning conditions for both groups. However, overall, the runners had a significantly larger amount $(10 \%)$ of non-REM sleep than did the nonrunners, but there were no such significant differences in SWS or in total sleep time. Indeed, physical fitness and not short-term increases in exercise levels may be the key factor in the exercise and sleep debate, as perhaps shown by Griffin and Trinder (1978). Fit and unfit subjects were required to run a standard distance. Although exercise had no effects upon the sleep of either group, fit subjects had more stage 3 sleep throughout the study. However, sleep disturbance, as judged by the amounts of wakefulness and light sleep, may have confounded these findings.

Reports of increases in SWS following daytime exercise may be associated with a heavy metabolic demand. For example, the study by Shapiro et al. (1975) imposed an exercise load of two to three times the moderately heavy load administered by Horne and Porter (1976). Other findings of increases in SWS and/or sleep-hGH release when the body is pushed to physiological limits come from starvation of nonobese subjects (MacFayden, Oswald, \& Lewis, 1973; Parker, Rossman, \& Vanderhaan, 1972) and heat stress (Putkonen, Eloman, \& Kotilanen, 1973).
Thyroid function also affects SWS, with hyperthyroidism resulting in SWS and sleep-hGH increases (Dunleavy, Oswald, Brown, \& Strong, 1974) and hypothyroidism leading to SWS decreases (Kales, Heuser, Jacobson, Kales, Hanley, Zweizig, \& Paulson, 1967). However, thyroid activity and SWS levels were not correlated in a group of healthy subjects exhibiting wide ranges of both parameters (Johns \& Rinsler, 1977). The reasons for all these effects upon SWS are unknown; all that can be said is that changes in SWS and sleep-hGH levels during or following physiological extremes may not provide clues to the normal functions of SWS or to the sleephGH release.

\section{Sedentary Life-Styles and Sleep}

As already noted, very low amounts of SWS have been reported in schizophrenic patients (Caldwell, 1969; Feinberg, Braun, Koresko, \& Gottlieb, 1969; Vigneri et al., 1974) and during depression (Shilkrut et al., 1975). Although there is a similar report from a study of blind persons (Krieger \& Glick, 1971), there is some contention over these findings (Weitzman, Perlow, Sassin, Fukushima, Burack, \& Hellman, 1972). It could be argued, from the more orthodox SWS and body restitution viewpoint, that schizophrenia, depression, and perhaps blindness lead to a sedentary way of life and low metabolic demands of wakefulness. Although this life-style might be so, and also explain why old people have little SWS (Williams, Karacan, \& Hursch, 1974), shorter term studies of completely immobilized people report that SWS levels are not reduced. Six weeks of prolonged bed rest in healthy young adults (Ryback \& Lewis, 1971) and 4-7 days of perceptual deprivation (Potter \& Heron, 1972) produced no changes in sleep quality.

While SWS may be quick to show an increase when the body is physiologically stressed, it may be slow in showing any decrease, and thus the short-term immobilization studies may not have been of sufficient length. The only study (Adey, Bors, \& Porter, 1968) of sleep in long-term immobility was on paraplegic and quadriplegic patients. Absolute and relative reductions of SWS as well as of REM sleep and total sleep time were reported, with the more extensively paralyzed quadriplegics showing greater reductions in these parameters than paraplegics. Although such findings could support a body restitutional hypothesis for SWS, it would seem strange that quadriplegics should need any body restitution during sleep, in view of the fact that the bulk of their voluntary musculature is always profoundly relaxed. But these patients still averaged $5 \mathrm{~h}$ of sleep a day. However, if human sleep facilitates cerebral restitution, then, although the mental abilities of these patients may be constrained by their environment, they will still 
need sleep. A final observation on this study is that the longer the period since the spinal lesion occurred, the less the SWS; a finding which might, indeed, suggest that SWS is slow to show reductions.

To summarize this discussion on human sleep and body restitution, it has been pointed out that: (1) human sleep-deprivation findings do not support such a role (but support a cerebral restitution role), (2) sleep-hGH release may be a misleading factor in the understanding of human sleep function, (3) plasma amino acid levels and metabolic rate during sleep mitigate against elevations in protein synthesis, (4) heightened mitotic rates are probably not causally related to sleep, and (5) exercise and sleep studies offer little support for a body restitutional role for human sleep. Thus, while, in man, sleep may only be an unnecessary, but convenient, vehicle for body restitutional processes, for other mammals which spend little of their wakefulness in a resting state, sleep may well be a necessary enforced immobilizer which allows for these processes to proceed at elevated levels.

Few would argue against a hypothesis that human sleep benefits the brain. However, what will be disputed here is that this benefit is synonymous only with REM sleep. But, before proposing that nonREM sleep, particularly SWS, may be equally important in this respect and that perhaps both REM and non-REM sleep interact to fulfill these proceses, it is noteworthy that evidence from a variety of sources attests to a demand for SWS which exceeds the demand for REM sleep. For example: SWS is more prominent soon after sleep onset and in the early sleep period than is REM sleep; a SWS rebound initially appears to take priority over a REM sleep rebound following total sleep deprivation (Horne, 1976; Kales, Tam, Kollar, Naitoh, Preston, \& Malstrom, 1970); although REM sleep is reduced in enforced, limited sleep regimes, the amount of SWS remains unchanged (Dement \& Greenberg, 1966; Mullaney, Johnson, Naitoh, Friedman, \& Globus, 1977; Webb \& Agnew, 1974); a similar finding is reported in natural shorter sleepers (Jones \& Oswald, 1968; Meddis, Pearson, \& Langford, 1973; Webb \& Agnew, 1970); and SWS is much harder to selectively deprive than is REM sleep (Agnew, Webb, \& Williams, 1967).

\section{Sleep and Cerebral Restitution}

Prior to discussing neurochemical and psychological phenomena which might relate to CNS restitution during sleep or in certain sleep states, some caveats must be made. First, it must be noted that the definition of SWS is arbitrary and that a less intense EEG slow-wave activity occurs in stage 2 sleep. Thus, SWS may not have qualitatively different roles from stage 2 sleep, but merely provide for more concentrated forms of some, or of all, of these roles.
Interestingly, Borbély (1978) has demonstrated that rats exhibit a deeper form of non-REM sleep at the beginning of a sleep period, indicating that the equivalent of human SWS may be present within the nonREM sleep of other mammals. Second, as most neurochemical studies of sleep are concerned with the rat and cat, inferences from these findings to man must be treated with caution. Third, a similar argument applies to sleep function. For example, Horne (1977) has argued that, as the phylogenetic scale is ascended, the primary role for sleep may change from one of body restitution and energy conservation to one of cerebral restitution.

REM sleep, unlike non-REM sleep, appears to be a state of intense neural activity with increases both in brain-blood flow and in brain temperature. These findings are used in support of REM sleep being the state of sleep associated with cerebral restitution. However, such findings and proposals need qualification, and it will be argued that REM sleep may not be so distinct from non-REM sleep.

While reduced physical activity in a voluntary muscle cell is considered by Adam and Oswald (1977) to provide for greater levels of anabolism, as already described, a parallel could be drawn with neuronal activity, whereby a high firing rate might mitigate against high amounts of anabolism within a neuron. Thus, the apparently high neural firing rates in REM sleep may not support ongoing high anabolic levels, but suggest that this anabolism is more likely in nonREM sleep. But it would seem that the differences in neural firing rates between these two sleep states are not so substantial as at first thought. Evarts (1961) was among the first to point out that, while the more easily recordable cortical neurons increased their activity during REM sleep, other neurons showed the reverse trend. He also suggested that many of these former cells may just be inhibitory neurons repressing other neurons which are more active during wakefulness. Later, Hobson and McCarley (1971) found, in a study of cortical unit activity in the cat, that the increases of neuronal activity during REM sleep were confined mostly to the phasic rather than the tonic component of REM sleep. Thus, the differences in firing rate between REM and non-REM sleep were accounted for during these phasic periods.

Creutzfeldt (1975) confirmed these latter views and noted, with Schlag (1974), that the salient feature of cortical neural activity during REM sleep may not be magnitude but temporal organization. Further support for this proposal comes from the following line of enquiry. Mink, Best, and Olds (1967) have reported that subcortical and brainstem neurons in the rat show a greater increase in discharge rates from nonREM to REM sleep than do cortical neurons. But, according to Moruzzi $(1966,1972)$, it is the cortex which requires sleep or "off-line restitution," not 
subcortical structures which can undergo "on-line restitution." Combining these two points, it would seem that increased firing rates during REM sleep are not synonymous with increased "off-line restitution."

An intriguing, but unanswerable, problem described by Creutzfeldt (1975) concerns his calculations that the increases in neural firing rate which are apparent during REM sleep only account for very small increases in neural metabolism. But indirect measures of brain metabolism, for example, brain blood flow, suggest that very large increases of metabolism occur during REM sleep. In the cat, subcortical blood flow doubles and cortical blood flow increases by $50 \%$ (Reis, Moorhead, \& Wooten, 1969; Reivich, Isaacs, Evarts, \& Kety, 1968). However, in man, the extent of this increase is debatable (Seylaz, Mamo, Goaz, \& Houdart, 1971; Townsend, Prinz, \& Obrist, 1973), but is probably much smaller than that in the cat. While larger increases in blood flow to subcortical areas may correspond to the relatively greater rate of neuronal firing during REM sleep in these areas, both Seylaz et al. and Townsend et al. consider that these blood flow changes are not due to increases in neuronal metabolism but are due to more central mechanisms. Seylaz et al. provide supportive evidence for this hypothesis-for example, the immediacy of the blood flow increase upon REM sleep onset, rather than a lag if neuronal metabolic activity were responsible.

Whether or not the rise in brain blood flow during REM sleep is central to REM sleep function or is just an epiphenomenon is a matter which must remain open to debate. However, the increase in brain temperature which occurs during REM sleep is probably an epiphenomenon (Hayward \& Baker, 1969). This increase appears to be explained, not through an elevation in heat production by neurons, but through a reduced rate of heat clearance from the brain by the blood, because blood entering the brain is warmer during REM sleep than in non-REM sleep. Details of this nonneural cause are described elsewhere (Horne, 1977).

During sleep, in general, there appears to be an increase in brain levels of ATP and a decrease in lactate (Durie et al., 1978; Reich, Geyer, \& Karnovsky, 1972; van den Noort \& Brine, 1970). While these biochemical conditions might favor cerebral restitution, it is still not clear from REM vs. non-REM sleepdeprivation studies whether either of these states might particularly favor such restitution, as there are many methodological difficulties involved in such studies. Karnovsky and Reich (1977), in their review of the neurochemical effects of sleep deprivation, consider that the majority of these studies do not provide adequate controls (p. 249) and that the observed increases may be an artifact of more extreme stress. Also, they propose that studies of protein syn- thesis inhibition which report reductions in REM sleep may not necessarily support a REM sleep and brain protein synthesis theory. All that may be happening is that REM-sleep-triggering mechanisms are interfered with, rather than REM sleep itself (p. 251). Finally, it must be remembered that these protein synthesis inhibitors, which are generally antibiotics, do have a variety of toxic effects.

Another approach which has been used in support of cerebral restitution being associated with REM sleep rather than with non-REM sleep comes from studies of sleep and learning, both in rodents and in man. Fishbein and Gutwein (1977), in their review of REM sleep and learning, claim that there is much evidence, from studies on rodents, mostly undergoing avoidance tasks, in support of a significant relationship between (1) the degree of learning and subsequent REM sleep, and (2) REM sleep deprivation and learning impairment. But, for other reviewers, the evidence is not so clear. Two years earlier, Albert (1975) concluded that any relationship between REM sleep and learning had not been clearly established. The most detailed and recent review (McGrath \& Cohen, 1978) adopts a more conciliatory position, and the following conclusions are arrived at: First, that REM sleep does not appear to prepare the organism for subsequent learning, and second, that, with several qualifications, REM sleep may facilitate (1) retention of the learning of unprepared or unusual material in both rats and man, and (2) divergent thinking in man. With animal studies attempting to show that increased learning is associated with greater amounts of subsequent REM sleep, McGrath and Cohen consider the tendency for an increase in the number, but not the duration, of REM sleep periods indicates that it is the integrity of the REM/non-REM sleep cycle rather than REM sleep per se which may be the key factor that facilitates learning.

The very few studies on the effects of more "reallife" learning situations upon REM sleep suggest that, if sleep were to be associated with cerebral restitution, then, in this respect, REM sleep is no better than non-REM sleep. If anything, non-REM sleep may be even better. The only major animal study of this nature was by Tagney (1973). Rats were reared in perceptually enriched environments for many days. If this rearing was from birth, then both REM and non-REM sleep were increased. But transfer to this environment later in life resulted in an increase only in non-REM sleep. Human studies of this kind have been of two main types: (1) increasing the amount of visual information processed by subjects during wakefulness, and (2) changing the quality of this information processed. Concerning the former, Horne (1976) and Horne and Walmsley (1976), in separate studies, assessed the effects of a high waking visual load upon subsequent sleep. The first inves- 
tigation also included 2 days of total sleep deprivation. A high-load condition contained a succession of visual scenarios which occupied much of wakefulness. A control condition contained a minimum of new visual input but equivalent amounts of auditory stimulation and exercise. Subjects underwent both conditions. The major finding from both studies was a significant increase in SWS over both recovery nights following the high visual load, when compared with the low-load condition. REM sleep was not affected.

With regard to the four human studies where the quality of the visual environment was affected, all but one of these (Zimmerman, Stoyva, \& Metcalf, 1970) reported no changes in subsequent sleep. Allen, Oswald, Lewis, and Tagney (1972) and Zimmerman et al. (1970) used inverting or distoring prisms, Bowe-Anders, Herman, and Roffwarg (1974) utilized tinted goggles, and Zimmerman, Stoyva, and Reite (1978) used tunnel-vision spectacles. While Zimmerman et al. (1970) reported a significant increase in REM sleep, this finding was later refuted by Zimmerman et al. (1978). Although all but Zimmerman et al. (1978) considered that new learning was taking place during wakefulness, visual input was severely restricted by the devices used. Thus, in terms of the quantity of visual processing, as described by Horne (1976) and Horne and Walmsley (1976), the load was reduced. This factor may have been responsible for the differences in SWS findings between these groups of studies.

Subtle roles for sleep within the human brain may be indicated from studies of divergent thinking ability and adaptability to new situations, following REM vs. non-REM sleep deprivation. For example, Glaubman, Orbach, Aviram, Freider, Frieman, Pelled, and Glaubman (1978) found that subjects performed significantly better at several aspects of divergent thinking following non-REM sleep deprivation than following REM sleep deprivationfindings which support a link between divergent thinking and REM sleep. However, divergent thinking is only a small part of human cognition, and the few studies on the effects of REM vs. non-REM or SWS sleep deprivation on other areas of cognition have shown little difference between these two deprivation conditions. Agnew et al. (1967) reported that seven nights of either REM sleep or SWS deprivation produced no significant differences in the degree of impairment between the two conditions, for a variety of fairly simple performance tasks. Later, Johnson (1973) reviewed a series of studies from his laboratory on the effects upon performance of, first, the recuperative value of REM sleep vs. SWS following total sleep deprivation, and second, the potentiation of total sleep deprivation by prior SWS or REM sleep deprivation. Although a variety of performance tasks were conducted, no performance differences were found between the effects of both conditions for either study. Johnson concluded that it is not so much a question of sleep quality which affects performance, but sleep quantity, and $3 \mathrm{~h}$ of sleep per day appear to be the minimum quantity required for the maintenance of normal performance levels.

While Johnson (1973) may be right, his conclusions are derived from a relatively limited range of tests which tended not to require a high degree of cognitive functioning. Thus, mechanisms central to human sleep functioning may not be tapped by these tests. To elaborate upon this point further, it must be noted that Naitoh (1975) and Wilkinson (1965), in their reviews of the psychological effects of sleep deprivation in man, have shown that the simpler and more uninteresting the task, the more it is affected by sleep deprivation. On the other hand, certain of the more involved tasks, like decision making, are more interesting, can help maintain subject motivation, and are less vulnerable to sleep deprivation. Such simpler tasks include reaction times, tracking, adding, card sorting, auditory vigilance, etc. Just because these simple tasks show significant effects of sleep deprivation, it cannot be assumed that these effects are related to the function of sleep per se, but perhaps indicate that subjects are more likely to get bored, particularly as these tasks often last for over $1 / 2 \mathrm{~h}$. Similarly, it cannot be assumed that because the interesting tasks are not so severely affected by sleep deprivation, these tasks are not related to sleep function. Therefore, a reason why these two types of task do not discriminate between the effects of REM and SWS sleep deprivation is that both tasks may be assessing motivation rather than more subtle sleep functions. Motivation impairment may be related to sleep loss per se, regardless of loss of sleep state. In order to determine those aspects of behavior in need of sleep, perhaps more everyday, cognitively demanding performance testing is necessary.

Proposals that non-REM sleep has an equally important role to play for cortical restitution as has REM sleep, have come from Feinberg (1974), Feinberg and Evarts (1969), and Laborit (1972). Laborit's neurochemical review of sleep concluded that mammalian non-REM sleep is a manifestation of increased anabolic activity in the neuroglia, while REM sleep appears to be an expression of higher metabolic activity in neurons. The relative abundance of 5-HT in the brain during non-REM sleep and the neurotransmitter's apparent influence in promoting anabolic processes in brain tissue was seen to be a key factor in this hypothesis. Feinberg and Evarts (1969) provided evidence in support of a hypothesis that, for man, SWS was a period during which substrates are synthesized for the restructuring of synapses during 
REM. However, later, Feinberg (1974) suggested a more complex interaction between these two types of sleep.

Finally, as already pointed out, SWS appears not to be a passive state of sleep. Creutzfeldt (1975) has indicated that the EEG of SWS may be due to a reduction in the thalamocortical drive system, resulting in a form of cortical isolation. The significance of this isolation is not clear, but there are experimental reports that during SWS the cerebral cortex is in a peculiar state of responsiveness. For example, sleepwalking predominates in SWS (Williams et al., 1974), and Sato, Dreifuss, and Penry (1975) conclude, from their EEG study of photic stimulation in epileptics, that the cortex appears to be functionally disconnected from subcortical mechanisms during SWS, a phenomenon not found in other sleep or waking states.

Thus, to conclude this discussion on cerebral restitution and human sleep, qualifactions of some of the neurophysiological phenomena accompanying REM sleep suggest that it might not be such a unique sleep state; SWS has its own peculiarities. Although REM sleep deprivation may be associated with certain types of learning and thinking detriments, there are other examples of behavior which do not differentiate the effects of non-REM sleep (primarily SWS) deprivation from REM sleep deprivation. However, the range of human behavior examined in this respect is limited, and more realistic assessments of human behavior are required. But, overall, it may well seem that both forms of sleep make an equal contribution towards cerebral restitution.

\section{REFERENCES}

Adam, K., \& Oswald, I. Sleep is for tissue restoration. Journal of the Royal College of Physicians, 1977, 11, 376-388.

Adamson, L., Hunter, W. M., Ogunremi, O. O., Oswald, I., \& Percy-RobB, I. W. Growth hormone increase during sleep after daytime exercise. Journal of Endocrinology, 1974, 62, 473-478.

Adey, W. R., Bors, E., \& Porter, R. W. EEG sleep patterns after high cervical lesion in man. Archives of Neurology, 1968, 19, 377-383.

Agnew, H. W., \& Weвb, W. B. The influence of time course variables on REM sleep. Bulletin of the Psychonomic Society, 1973, 2, 131-133.

Agnew, H., Webb, W. G., \& Williams, R. L. Comparison of stage 4 and 1-REM sleep deprivation. Perceptual and Motor Skills, 1967, 24, 851-858.

Albert, I. B. REM sleep deprivation. Biological Psychiatry, 1975, 10, 341-349.

Alford, F. B., Baker, H. W. G., \& Burger, H. G. The secretion of human growth hormone, 1 . Daily secretion rates, effects of posture and sleep. Journal of Clinical Endocrinology and Metabolism, 1973, 37, 515-520.

Allen, S. R., Oswald, I., Lewis, S. A., \& Tagney, J. Effects of distorted visual input on sleep. Psychophysiology, 1972, 9, 498-504.

Atrinson, D. E. The energy charge of the adenylate pool as a regulatory parameter. Interaction with feedback modifiers. Biochemistry, 1968, 7, 4030-4034.
Atrinson, D. E. Enzymes as control elements in metabolic regulation. In P. D. Boyer (Ed.), The enzymes (Vol. 1). New York: Academic Press, 1970.

BAEKeland, F., \& LASKy, R. Exercise and sleep patterns in college athletes. Perceptual and Motor Skills, 1966, 23, 1203-1207.

Blackard, W. G., \& Andrews, S. S. Integration of the secretary control mechanisms for insulin, glucagon, and growth hormone. Current Topics in Experimental Endocrinology, 1974, 2, 129-153.

BorBÉLY, A. Effects of light on sleep and activity rhythms. Progress in Neurobiology, 1978, 10, 1-31.

Bowe-Anders, C., Herman, J., \& Roffwarg, H. Effects of goggle altered color perception on sleep. Perceptual and Motor Skills, 1974, 38, 191-198.

Brebbia, D. R., \& Altshuler, K. Z. Oxygen consumption rate and electroencephalographic stage of sleep. Science, 1965, 150, 1621-1623.

Caldwell, D. F. Differential levels of stage 4 sleep in a group of clinically similar chronic schizophrenic patients. Biological Psychiatry, 1969, 1, 131-141.

Clark, R. H., \& Korst, D. R. Circadian periodicity of bone marrow mitotic activity and reticulocyte counts in rats and mice. Science, 1969, 166, 236-237.

Cooper, Z. K. Mitosis rhythms in human epidermis. Journal of Investigative Dermatology, 1939, 2, 289-301.

Creutzfeldt, O. D. Neurophysiological correlates of different functional states of the brain. In D. H. Ingvar \& N. A. Lassen (Eds.), Brain work. Copenhagen: Munksgaard, 1975.

Dement, W. C., \& Greenberg, S. G. Changes in total amount of stage four sleep as a function of partial sleep deprivation. Electroencephalography and Clinical Neurophysiology, 1966, 20, 523-526.

Drucker-Colin, R. R., Spanis, C. W., \& Rojas-Ramerez, J. A. Investigation of proteins in REM sleep. In R. R. DruckerColin \& J. L. McGaugh (Eds.), Neurobiology of sleep and memory. New York: Academic Press, 1977.

Dunleavy, D. L. F., Oswald, I., Brown, P., \& Strong, J. A. Hyperthyroidism, sleep and growth hormone. Electroencephalogry and Clinical Neurophysiology, 1974, 36, 259-263.

Durie, D. J. B., Adam, K., Oswald, I., \& Flynn, I. W. Sleep: Cellular energy charge and protein synthetic capability. IRCS Medical Science, 1978, 6, 351.

Evarts, E. V. Effects of sleep and waking on activity of single units in the unrestrained cat. In G. E. W. Wolstenholme \& M. O'Connor (Eds.), The nature of sleep. London: Churchill, 1961.

Feigin, R. D., Klainer, A. S., \& Beisel, W. R. Circadian periodicity of blood amino acids in adult man. Nature, 1967, 215, 512-514.

Feinberg, I. Changes in sleep cycle patterns with age. Journal of Psychiatric Research, 1974, 10, 283-306.

Feinberg, I., Braun, M., Koresko, R. L., \& Gottlieb, F. Stage 4 sleep in schizophrenia. Archives of General Psychiatry, $1969,21,262-275$.

Feinberg, I., \& Evarts, E. V. Changing concepts of the function of sleep: Discovery of intense brain activity during sleep calls for revision of hypothesis as to its function. Biological Psychiatry, 1969, 1, 331-348.

Fishbein, W., \& Gutwe in, B. M. Paradoxical sleep and memory storage processes. Behavioral Biology, 1977, 19, 425-464.

Fishe R, L. B. The diurnal mitotic rhythm in the human epidermis. British Journal of Dermatology, 1968, 80, 75-80.

Garlick, P. J., Clugston, G. A., Swick, R. W., Meinertzhagen, I. H., \& WATE RLOW, J. C. Diurnal variations in protein metabolism in man. Proceedings of the Nutrition Society, 1978, 37, $33 \mathrm{~A}$.

Garma, L., Verley, R. Ontogénese des états de veille et de sommeil chez pez mammifères. Revue Neuropsychiatrie Infante, $1969,17,487-504$. 
Glaubman, H., Orbach, I., Aviram, O., Freider, I., Frieman, M., Pelled, O., \& Glaubman, R. ReM deprivation and divergent thinking. Psychophysiology, 1978, 15, 75-79.

Golden, M. H. N., \& Waterlow, J. C. Total protein synthesis in elderly people. Clinical Science and Molecular Medicine, 1977, 53, 277-288.

Griffin, S. J., \& Trinder, J. Physical fitness, exercise and human sleep. Psychophysiology, 1978, 15, 447-450.

Halberg, F., \& Barnum, C. P. Continuous light or darkness and circadian periodic mitosis and metabolism in $C$ and $D_{8}$ mice. American Journal of Physiology, 1961, 201, 227-230.

Hartmann, E. The functions of sleep. New Haven: Yale University Press, 1973.

Hayward, J. M., \& Baker, M. A. A comparative study of the role of the cerebral arterial blood in the regulation of brain temperature in five mammals. Brain Research, 1969, 16, 417-440.

Hobson, J. A., \& McCarley, R. W. Cortical unit activity in sleep and waking. Electroencephalography and Clinical Neurophysiology, 1971, 30, 97-112.

Honda, Y., Takahashi, K., Takahashi, S., Azumi, K., Irie, M., Sakuma, M. Tsushima, T., \& Schizume, K. Growth hormone secretion during nocturnal sleep in normal subjects. Journal of Clinical Endocrinology, 1969, 29, 20-29.

HoRne, J. A. Recovery sleep following different visual conditions during total sleep deprivation in man. Biological Psychology, 1976, 4, 107-118.

Horne, J. A. Factors relating to energy conservation during sleep in mammals. Physiological Psychology, 1977, 5, 403-408.

Horne, J. A. A review of the biological effects of total sleep deprivation in man. Biological Psychology, 1978, 7, 55-102.

Horne, J. A., \& Porter, J. M. Time of day effects with standardised exercise upon subsequent sleep. Electroencephalography and Clinical Neurophysiology, 1976, 40, 178-184.

Horne, J. A., \& Walmsley, B. Daytime visual load and the effects upon sleep. Psychophysiology, 1976, 13, 115-120.

Hunter, W. M. Secretion of human growth hormone. Proceedings of the Nutrition Society, 1972, 31, 199-203.

Jacobson, A., Kales, A., Lehmann, D., \& Hoedemaker, F. S. Muscle tonus in human subjects during sleep and dreaming. Experimental Neurology, 1964, 10, 418-424.

Johns, M. W., \& Rinsler, M. G. Sleep and thyroid function: Further studies in healthy young men. Journal of Psychosomatic Research, 1977, 21, 161-166.

Johnson, L. C. Are stages of sleep related to waking behavior? American Scientist, 1973, 61, 326-337.

Jones, H. S., \& Oswald, I. Two cases of healthy insomnia. Electroencephalography and Clinical Neurophysiology, 1968, 24, 378-380.

Kales, A., Heuser, G., Jacobson, S., Kales, J. D., Hanley, J., Zweizig, J. R., \& Paulson, M. J. All night sleep studies in hypothyroid patients, before and after treatment. Journal of Clinical Endocrinology, 1967, 27, 1593-1599.

Kales, A., Tam, T., Kollar, E. J., Naitoh, P., Preston, T. A., \& Malstrom, E. J. Sleep patterns following 205 hours of sleep deprivation, Psychosomatic Medicine, 1970, 32, 189-200.

Karacan, I., Rosenbloom, A. L., Londono, J. H., Williams, R. L., \& SAlis, P. J. Growth hormone levels during morning and afternoon naps. Behavioral Neuropsychiatry, 1974, 6, 67-70.

Karacan, I., Rosenbloom, A. L., Williams, R. L., Finley, W. W., \& HurSCH, C. J. Slow wave sleep deprivation in relation to plasma growth hormone concentration. Behaviora! Neuropsychiatry, 1971, 2, 11-14.

Karacan, I., Williams, R. L., Finley, W. W., \& Hursch, C. J. The effects of naps on nocturnal sleep: Influence on the need for stage 1 REM and stage 4 sleep. Biological Psychiatry, 1970, 2, 391-399.

Karnovsky, M. L., \& Reich, P. Biochemistry of sleep. Advances in Neurochemistry, 1977, 2, 213-275.
Kostyo, J. L., \& NutTing, D. F. Growth hormone and protein metabolism. In American Physiological Society Handbook of Physiology (Section 7, Vol. IV). Baltimore: Williams \& Wilkins, 1974.

Kreider, M. B., Buskirk, E. R., \& Bass, D. E. Oxygen consumption and body temperatures during the night. Journal of Applied Physiology, 1958, 12, 361-366.

KRIEGER, D. T., \& GLICK, S. Absent sleep peak of growth hormone release in blind subjects. Journal of Clinical Endocrinology, 1971, 33, 847-850.

LABORIT, H. Correlations between protein and serotonin synthesis during various activities of the central nervous system. Research Communications in Chemical Pathology and Pharmacology, 1972, 3, 51-81.

Lipman, R. L., Taylor, A. L., Schenk, A., \& Mintz, D. H. Inhibition of sleep related growth hormone release by elevated free fatty acids. Journal of Clinical Endocrinology and Metabolism. 1972, 36, 592-594.

Lucke, C., Höffken, B., \& von zur Mühlen, A. Studies on the postponed growth hormone secretion following the infusion of somatostatin. Acta Endocrinologica, 1976, 82, 400-466.

MacFadyen, U. M., Oswald, I., \& Lewis, S. A. Starvation and human slow wave sleep. Journal of Applied Physiology, 1973, 35, 391-394.

MARTIN, C. R. Textbook of endocrine physiology. Baltimore: Williams \& Wilkins, 1977.

Mauer, A. M. Diurnal variation of proliferative activity in the human bone marrow. Blood, 1965, 26, 1-7.

McGrath, M. J., \& Cohen, D. B. REM sleep facilitation of adaptive waking behavior: A review of the literature. Psychological Bulletin, 1978, 85, 24-57.

Meddis, R., Pearson, A. J. D., \& Langford, G. An extreme case of healthy insomnia. Electroencephalography and Clinical Neurophysiology, 1973, 35, 391-394.

Mink, W. D., Best, P. J., \& Olds, J. Neurones in paradoxical sleep and motivated behavior. Science, 1967, 158, 1335-1337.

Moruzzi, G. The functional significance of sleep with particular regard to the brain mechanisms underlying consciousness. In J. C. Eccles (Ed.), Brain and conscious experience. Berlin: Springer-Verlag, 1966.

Moruzzı, G. The sleep-waking cycle. Reviews of Physiology, $1972,64,1-165$.

Moses, J., Lubin, A., Naitoh, P., \& Johnson, L. C. Exercise and sleep loss: Effects on recovery sleep. Psychophysiology, 1977, 14, 414-416.

Mullaney, D. C., Johnston, L. C., Naitoh, P., Friedman, J. K., \& GlobUS, G. G. Sleep during and after gradual sleep reduction. Psychophysiology, 1977, 14, 237-244.

NaItoH, P. Sleep deprivation in humans. In P. H. Venables \& M. J. Christie (Eds.), Research in psychophysiology, New York: Wiley, 1975.

Orr, W. C., Vogel, G. W., Stahl, M. L., Griffiths, W. J., \& SeELY, J. R. Sleep patterns in growth hormone deficient children and age-matched controls: Developmental considerations. Neuroendocrinology, 1977, 24, 347-352.

OswaLd, I. Human brain protein, drugs and dreams. Nature, 1969, 223, 893-897.

Oswald, I. The function of sleep. Postgraduate Medical Journal, 1976, 52, 15-18.

Parker, D. C., \& Rossman, L. G. Human growth hormone release in sleep: Non-suppression by acute hyperglycaemia. Journal of Clinical Endocrinology, 1971, 32, 65-69.

Parker, D. C., Rossman, L. G., \& Vanderhaan, E. F. Persistence of rhythmic growth hormone release during sleep in fasted and non-isocalorically fed normal subjects. Metabolism, 1972, 21, 241-252.

Potter, W., \& Heron, W. Sleep during perceptual deprivation. Brain Research, 1972, 40, 534-539.

Putkonen, P. T. S., Eloman, E., \& Kotilanen, P. V. Increase 
in delta $(3+4)$ sleep after heat stress in sauna. Scandinavian Journal of Clinical and Laboratory Investigation, 1973, Suppl. $130,19$.

QuABBE, H-J. Chronobiology of growth hormone secretion. Chronobiologia, 1977, 4, 217-246.

Reich, P., Geyer, S. J., \& Karnovsky, M. L. Metabolism of brain during sleep and wakefulness. Journal of Neurochemistry, $1972,19,487-497$.

Reis, D. J., Moorhead, D., \& Wotten, G. F. Differential regulation of blood flow to red and white muscle in sleep and defensive behavior. American Journal of Physiology, 1969, 27, 541-546.

Reivich, M., Isaacs, G., Evarts, E., \& Kety, S. The effect of slow wave sleep and REM sleep on regional cerebral blood flow in cats. Journal of Neurochemistry, 1968, 15, 301-306.

Ryваск, R. S., \& Lewis, O. F. Effects of prolonged bed rest on EEG sleep patterns in young, healthy volunteers. Electroencephalography and Clinical Neurophysiology, 1971, 31, 395-399.

Sassin, J. F. Sleep-related hormones. In R. R. Drucker-Colin \& J. L. McGaugh (Eds.), Neurobiology of sleep and memory. New York: Academic Press, 1977.

Sassin, J. F., Parker, D. C., Johnson, L. C., Rossman, L. G., MACE, J. W., \& Gothin, R. W. Effects of slow wave sleep deprivation on human growth hormone release in sleep: Preliminary study. Life Sciences, 1969, 8, 1299-1307.

Sato, S., Dreifuss, F. E., \& Penry, J. K. Photic sensitivity of children with absence seizures in slow wave sleep. Electroencephalography and Clinical Neurophysiology, 1975, 39, 479-489.

Schlag, J. Reticular influences on thalamo-cortical activity. In A. Remond (Ed.), Handbook of electroencephalography and clinical neurophysiology (Vol. 2, Part C). Amsterdam: Elsevier, 1974.

Schilkrut, R., Chandra, O., Osswald, M., Ruther, E., BaARTÜSSAR, B., \& MatusseK, N. Growth hormone release during sleep and with thermal stimulation with depressed patients. Neuropsychobiology, 1975, 1, 70-79.

Schnure, J. J., Raskin, P., \& Lipman, R. L. Growth hormone secretion during sleep: Impairment in glucose tolerance and non-suppressability by hyperglycaemia. Journal of Clinical Investigation, 1971, 33, 234-241.

Seylaz, J., Mamo, H., Goas, J. Y., \& Houdart, R. Human cerebral blood flow regulation and physiological sleep. In R. W. Russel (Ed.), Brain and blood flow. London: Pitman, 1971.

Shapiro, C. M., Griesel, R. D., Bartel, P. R., \& Jooste, P. L. Sleep patterns after graded exercise. Journal of Applied Physiology, 1975, 2, 187-190.

Stern, W. C., \& Morgane, P. J. Sleep and memory: Effects of growth hormone on sleep brain neurochemistry and behavior. In R. R. Drucker-Colin \& J. L. McGaugh (Eds.), Neurobiology of sleep and memory. New York: Academic Press, 1977.

Sutron, J., \& Lazarus, L. Growth hormone in exercise: Comparison of physiological and pharmacological stimuli. Journal of Applied Physiology, 1976, 41, 523-527.

TAGNEY, J. Sleep patterns related to rearing rats in enriched and impoverished environments. Brain Research, 1973, 53, 353-361.

Takahashi, Y., Kipnis, D. M., \& Daughaday, W. H. Growth hormone secretion during sleep. Journal of Clinical Investigation, 1968, 47, 2079-2090.
Townsend, R. E., Prinz, P. N., \& Obrist, W. D. Human cerebral blood flow during sleep and waking. Journal of Applied Physiology, 1973, 35, 620-625.

VAN DEN Noort, S., \& Brine, K. Effect of sleep on brain labile phosphates and metabolic rate. American Journal of Physiology, 1970, 218, 1434-1439.

Vigneri, R., Pezzino, V., Squatrito, S., Calandara, A., \& MaRicchiolo, M. Sleep-associated growth hormone release in schizophrenia. Neuroendocrinology, 1974, 14, 356-361.

Walker, J. M., Floyd, T. C., Fein, G., Cavness, C., Lualhati, R., \& Feinberg, I. Effects of exercise on sleep. Journal of Applied Physiology, 1978, 44, 945-951.

Waterlow, J. C., Garlick, P. J., \& Millward, D. J. Protein turnover in mammalian tissues and in the whole body. Amsterdam: Elsevier, 1978.

Weвв, P., \& Hiestand, M. Sleep metabolism and age. Journal of Applied Physiology, 1975, 38, 257-262.

Weвb, W. B., \& Agnew, H. W. Sleep stage characteristics of long and short sleepers. Science, 1970, 168, 146-147.

Wевв, W. B., \& Agnew, H. W. Stage 4 sleep: Influence of time course variables. Science, 1971, 174, 1354-1356.

Weвb, W. B., \& Agnew, H. W. The effects of a chronic limitation of sleep length. Psychophysiology, 1974, 11, 265-274.

WebB, W. B., \& AgneW, H. W. Analysis of the sleep stages in sleep-wakefulness regimens of varied length. Psychophysiology, 1977, 14, 445-450.

Weitzman, E. D. Circadian rhythms and episodic hormone secretion in man. Annual Review of Medicine, 1976, 27, 225-243.

Weitzman, E. D. Memory and sleep: Neuroendocrinological considerations. In R. R. Drucker-Colin \& J. L. McGaugh (Eds.), Neurobiology of sleep and memory. New York: Academic Press, 1977.

Weitzman, E. D., Perlow, M., Sassin, J., Fukushima, D., Burack, B., \& Hellman, L. Transactions of the American Neurological Association, 1972, 97, 197-199.

Wilkinson, R. T. Sleep deprivation. In O. G. Edholm \& A. L. Bacharach (Eds.), Physiology of survival. London: Academic Press, 1965.

Williams, R. L., Karacan, I., \& Hursch, C. J. Electroencephalography (EEG) of human sleep: Clinical applications. New York: Wiley, 1974.

Young, V. R., Steffee, W. P., Pencharz, P. B., Winterer, J. G., \& Scrimshaw, N. S. Total human body protein synthesis in relation to protein requirements at various ages, Nature, 1975, 253, 192-194.

Zimmerman, J. T., Stoyva, J., \& Metcalf, D. Distorted visual feedback and augmented REM sleep. Psychophysiology, 1970, 7, 298-306.

Zimmerman, J. T., Stoyva, J. M., \& Reite, M. L. Spatially re-arranged vision and REM sleep: A lack of effect. Biological Psychiatry, 1978, 13, 301-316.

Zir, L. M., Smith, R. A., \& Parker, D. C. Human growth hormone release in sleep: Effect of daytime exercise. Journal of Clinical Endocrinology, 1971, 32, 662-665.

Zloty, R. B., Burdick, J. A., \& Adamson, J. D. Sleep of long distance runners. Activitas Nervosa Superior, 1973, 15, 217-221.

(Received for publication March 7, 1978; revision accepted April 10, 1979.) 